\title{
Efficacy of Hyaluronic Acid Injections versus Steroid Injections on Painful Tendinopathies
}

\author{
Marina Saif Azmy, Ibtesam K. Ali, Ahmed R. Radwan*, Mohammed Ali Ismail
}

Department of Physical medicine, Rheumatology and Rehabilitation - Faculty of Medicine- Sohag University, Egypt. *Corresponding author: Ahmed R. Radwan, Mobile: (+20) 1092914019, Email: ahmed_radwan@med.sohag.edu.eg

\begin{abstract}
Background: Tendinopathies are manifested by pain, swelling, and limited mobility functions. Corticosteroid injections have been a mainstay in the treatment of tendinopathy, and are widely used despite the controversy regarding their usefulness and safety. The peri-tendinous administration of hyaluronic acid (HA) has shown promising results in the management of tendinopathy.

Objectives: The aim of the current study was to evaluate the efficacy of peri-tendinous injections of hyaluronic acid versus steroid injections on pain reduction in patients with painful tendinopathies.

Patients and methods: A prospective study, including a total of 90 patients with tendinopathy who were recruited from the Rheumatology and Rehabilitation Outpatient Clinic at Sohag University Hospital. Demographic data including age, disease duration, and tendon affected were evaluated. Patients were divided into three groups, each group contained 30 patients. First group received peritendinous steroid injection, second group received peritendinous hyaluronic acid injection, and the third group received both peritendinous hyaluronic acid and steroid injections. Groups were compared using in visual analogue scale, tenderness and range of motion after one week, one month and after 3 months from injection.

Results: Best improvement was seen in the group of combined hyaluronic acid and steroid; followed by the group of steroid injection alone, which showed early response better than hyaluronic acid alone.

Conclusion: Local injection for tendinopathies by combined hyaluronic acid and steroid gives significantly better and more long standing effect compared to either hyaluronic acid or steroid alone. On the other hand, monotherapy showed non-significant difference between steroid and hyaluronic acid.
\end{abstract}

Keywords: Tendinopathy, Steroid, Hyaluronic acid.

\section{INTRODUCTION}

Tendinopathies comprise a group of tendon disorders manifested by pain, swelling, and limited mobility functions. Typically, pain is worse with movement and improved by rest. The most commonly involved tendons include those around the shoulder (rotator cuff tendinitis, biceps tendinitis), elbow (tennis elbow, golfer's elbow), wrist, hip, knee (jumper's knee) and ankle (Achilles tendinitis) ${ }^{(\mathbf{1})}$. Causes may include an injury or repetitive activities such as tennis. Less common causes include infection, arthritis, gout, thyroid disease, and diabetes ${ }^{(2)}$.

Oral and local non-steroidal anti-inflammatory drugs (NSAIDs) appear effective in the treatment of acute shoulder bursitis/tendonitis ${ }^{(3,4)}$.

Stretching and strengthening exercise programs are common physiotherapeutic modalities in most programs planned for management of tendinopathy. Other modalities may include therapeutic ultrasound, iontophoresis, deep transverse friction massage, laser therapy and hyperthermia ${ }^{(5)}$.

Also, extracorporeal shock wave therapy (ESWT) is a rapidly growing option, with good outcome evidence in the treatment of calcific tendinopathy ${ }^{(6)}$.

Corticosteroid injections have been a mainstay in the treatment of tendinopathy, and are widely used globally, despite the controversy regarding their usefulness and safety in these cases ${ }^{(7,8)}$.
Platelet-rich plasma (PRP) is achieving growing evidence regarding its usefulness in many fields of medicine owing to its possibilities in enhancing tissue regeneration ${ }^{(9)}$.

The anti-inflammatory and lubrication properties of HA have been drew the scientific community's interest to treat tendinopathies. HA is a polysaccharide present in the extra cellular matrix of many mature tissues. Many chronic injuries could change the concentration of HA in the synovial fluid ${ }^{(\mathbf{1 0})}$.

Experiments conducted on human macrophages have shown its ability to interfere with the expression of PGE2 and of the cyclooxygenase 2. Further mechanisms contributing to the anti-nociceptive effect are the inhibition of arachidonic acid release from fibroblasts and the activation of opioid receptors ${ }^{(11)}$.

Actually, there are many studies about HA injections in the management of tendons disorders ${ }^{(\mathbf{1 2})}$. The peritendinous administration of HA has shown promising results in the management of tennis elbow ${ }^{(13)}$, patellar tendinopathy ${ }^{(14)}$, Achilles tendinopathy ${ }^{(15}$, 16), and tendons in the rotator cuff ${ }^{(17,18)}$. Although the mechanisms of action in the treatment of tendinopathies are not well understood, peritendinous injection of HA may reduce tendon adhesion, provide mechanical protection, and upregulate the vascular endothelial growth factor and type IV collagen, leading to acceleration of tendon healing ${ }^{(\mathbf{1 9})}$. 
The current study aimed to evaluate the efficacy of peri-tendinous injections of $\mathrm{HA}$ in comparison to steroid injections and combination of both modalities on pain reduction in patients with painful tendinopathies.

\section{PATIENTS AND METHODS}

This study included 90 patients with tendinopathy who were recruited from the Rheumatology and Rehabilitation Outpatient Clinic at Sohag University Hospital.

\section{Inclusion criteria:}

- Male or female patients aged $\geq 18$ years.

- Patients in the symptomatic phase of chronic tendinopathy, characterized by presence of at least one among: tendon swelling, pain on palpation, pressure and/or prehension, painful limited range of motion).

\section{Exclusion criteria:}

- Patients with recent tendon surgery.

- Pregnant or breast-feeding females.

\section{Patients were evaluated as follow:}

1- All patients were interviewed for demographic data including age, disease duration, and tendon affected.

2- All patient were divided into three groups, each group contained 30 patients.

a. The first group received peritendinous HA injection.

b. The second group received peritendinous steroid injection.

c. The third group received both peritendinous $\mathrm{HA}$ and steroid injections.

3- We compared between two groups in VAS (visual analogue scale), tenderness and range of motion after one week and after one month from injection.

\section{Ethical approval:}

An approval of the study was obtained from Sohag University Academic and Ethical Committee. Each participant was informed about the research objective and methods in detail and using simple language prior to being requested to provide written informed consent prior to participation in the research. This work has been carried out in accordance with The Code of Ethics of the World Medical Association (Declaration of Helsinki) for studies involving humans.

\section{Statistical analysis}

The collected data were coded, processed and analyzed using the SPSS (Statistical Package for Social Sciences) version 22 for Windows ${ }^{\circledR}$ (IBM SPSS Inc, Chicago, IL, USA). Data were tested for normal distribution using the Shapiro Walk test. Qualitative data were represented as frequencies and relative percentages. Chi square test $\left(\chi^{2}\right)$ to calculate difference between two or more groups of qualitative variables. Quantitative data were expressed as mean \pm SD. Independent samples t-test was used to compare between two independent groups of normally distributed variables (parametric data). $\mathrm{P}$ value $\leq 0.05$ was considered significant.

\section{RESULTS}

The mean age of the study groups was $45.8 \pm 6.4$ years, two thirds of the study groups were females $(63.3 \%)$, more than half of the cases were from rural areas, and only $42 \%$ were from urban areas. The mean disease duration of the study groups was around 1 year (12.7-13 months) with a range from 6 months to 2 years (Table 1).

Table (1): Demographic and basic clinical data of the study population

\begin{tabular}{lccccc}
\hline \multicolumn{1}{l}{ Group } & & Hyaluronic acid & Steroid & $\begin{array}{c}\text { Hyaluronic acid + } \\
\text { Steroid }\end{array}$ & P value \\
\hline Mean age (years) & & $45.13 \pm 6.71$ & $46.13 \pm 6.57$ & $46.20 \pm 6.11$ & 0.775 \\
Sex & Male & $12(40 \%)$ & $10(33.3 \%)$ & $11(36.7 \%)$ & 0.866 \\
& Female & $18(60 \%)$ & $20(66.7 \%)$ & $19(63.3 \%)$ & \\
Residence & Urban & $13(43.3 \%)$ & $12(40 \%)$ & $13(43.3 \%)$ & 0.955 \\
\multicolumn{2}{l}{ Disease duration (months) } & $17(56.7 \%)$ & $18(60 \%)$ & $17(56.7 \%)$ & \\
\end{tabular}

Regarding the site of injection, the majority of cases had shoulder area tendinopathies, with only around one quarter of the cases had trigger fingers and around $10 \%$ had plantar fasciitis. The distribution of the site of injection was comparable among the three groups with no significant differences (Table 2). 
Table (2): Site of injection

\begin{tabular}{lccc}
\hline & $\begin{array}{c}\text { Group 1 } \\
\text { (HA) }\end{array}$ & $\begin{array}{c}\text { Group 2 } \\
\text { (Steroid) }\end{array}$ & $\begin{array}{c}\text { Group 3 } \\
\text { (HA + steroid) }\end{array}$ \\
\hline Bicipital tendinitis & $4(13.3 \%)$ & $6(20 \%)$ & $7(23.3 \%)$ \\
Supraspinatus tendinitis & $5(16.7 \%)$ & $5(16.7 \%)$ & $9(30 \%)$ \\
Other shoulder tendinopathies & $7(23.3 \%)$ & $8(26.7 \%)$ & $4(13.3 \%)$ \\
Trigger fingers & $11(36.7 \%)$ & $7(23.3 \%)$ & $8(26.7 \%)$ \\
Plantar fasciitis & $3(10 \%)$ & $4(13.3 \%)$ & $2(6.7 \%)$ \\
\hline
\end{tabular}

Chi square $=5.572, \mathrm{P}$ value $=0.695$

Regarding the comparison of VAS among the three groups (using ANOVA test) at different follow up intervals, we found that there was no significant difference among the three groups regarding the baseline VAS. However, after injection, we found that the lowest VAS was recorded in the group of combined HA and steroid injection (group 3) followed by steroid group (group 2) and lastly the group of HA alone (group 1) with significant differences. This was maintained all over the follow up period at one week, 4 weeks and 3 months post-injection (Table 3 ).

Table (3): VAS comparison among the three groups at baseline, after 2 weeks, 4 weeks and 3 months

\begin{tabular}{lccccc}
\hline \multicolumn{1}{c}{ VAS } & $\begin{array}{c}\text { Group 1 } \\
\text { (HA) }\end{array}$ & $\begin{array}{c}\text { Group 2 } \\
\text { (Steroid) }\end{array}$ & $\begin{array}{c}\text { Group 3 } \\
(\text { HA + steroid })\end{array}$ & ANOVA & P value \\
\hline At baseline & $9.00 \pm 0.743$ & $8.97 \pm 0.809$ & $9.03 \pm 0.615$ & 0.063 & 0.939 \\
After 2 weeks & $5.50 \pm 2.316$ & $4.83 \pm 2.183$ & $3.90 \pm 1.749$ & 4.409 & $\mathbf{0 . 0 1 5}$ \\
After 4 weeks & $5.03 \pm 2.236$ & $4.63 \pm 2.042$ & $3.73 \pm 1.461$ & 3.530 & $\mathbf{0 . 0 3 4}$ \\
After 3 months & $5.20 \pm 2.107$ & $5.13 \pm 2.129$ & $3.57 \pm 1.223$ & 7.345 & $\mathbf{0 . 0 0 1}$ \\
\hline
\end{tabular}

Regarding the comparison of VAS between each two groups, we found that there were non-significant differences between group 1 and group 2 all over the study duration. The improvement among steroid group was slightly higher than HA group at early stage, but the improvement among HA group was more sustained for as long as 12 weeks postinjection. On the other hand, there were significant differences between group 1 and 3 regarding VAS from as early as one week after the injection and this was sustained till the end of 12 weeks follow up period. Lastly, there was a significant difference between group 2 and group 3 regarding VAS only at 12 weeks after the injection (Table 4).

Table (4): VAS comparison between each two groups at baseline, after 2 weeks, 4 weeks and 3 months

\begin{tabular}{lcccccc}
\multicolumn{1}{c}{ VAS } & $\begin{array}{c}\text { Group 1 } \\
\text { (HA) }\end{array}$ & $\begin{array}{c}\text { Group 2 } \\
\text { (Steroid) }\end{array}$ & $\begin{array}{c}\text { Group 3 } \\
\text { (HA + steroid) }\end{array}$ & \multicolumn{2}{c}{$\begin{array}{c}\text { Individual comparison p } \\
\text { values } \\
\text { (using student t test) }\end{array}$} \\
\cline { 5 - 7 } & & & & & & \\
\hline At baseline & $9.00 \pm 0.743$ & $8.97 \pm 0.809$ & $9.03 \pm 0.615$ & 0.869 & 0.850 & 0.721 \\
After 2 weeks & $5.50 \pm 2.316$ & $4.83 \pm 2.183$ & $3.90 \pm 1.749$ & 0.256 & $\mathbf{0 . 0 0 4}$ & 0.073 \\
After 4 weeks & $5.03 \pm 2.236$ & $4.63 \pm 2.042$ & $3.73 \pm 1.461$ & 0.472 & $\mathbf{0 . 0 1 0}$ & 0.054 \\
After 3 months & $5.20 \pm 2.107$ & $5.13 \pm 2.129$ & $3.57 \pm 1.223$ & 0.903 & $\mathbf{0 . 0 0 1}$ & $\mathbf{0 . 0 0 1}$ \\
\hline
\end{tabular}

We found that the best improvement was in the group of combined HA and steroid, and this was seen since 1 week post-injection, and continued to improve till the end of the 12 weeks follow up. This was followed by the group of steroid injection alone, which showed early response better than HA alone, but this response started to decline at the end of the study duration, with gradual approximation to the results of the group of HA alone, which showed later but more sustained response (Figure 1). 


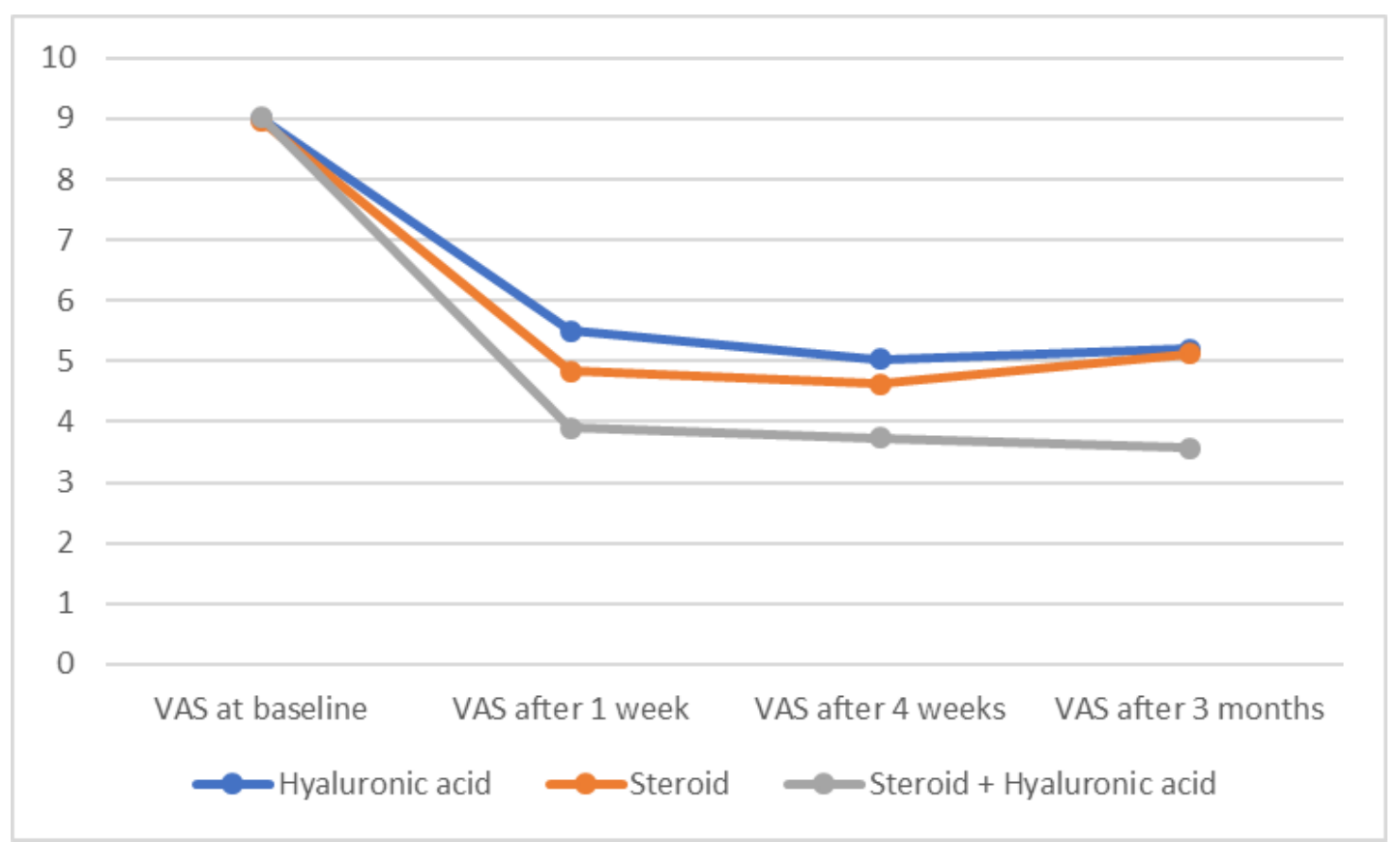

Figure (1): Comparison of VAS among the three groups all over the study period

\section{DISCUSSION}

Tendinopathies are multifactorial clinical conditions, which affect millions of people, producing disability that may last for several months ${ }^{(20)}$. Even mechanical overloading is considered as the main risk factor, other intrinsic and extrinsic factors may contribute to the pathogenesis ${ }^{(21)}$. In particular, poor vascularity, underload, age, gender, as well as genetic, endocrine and metabolic factors may play a central role (22).

Over the last decade, various models have been proposed to explain the intrinsic pathogenic mechanism of tendinopathies, which determine the failed healing response. Chronic cases are characterized by increased tenocyte apoptosis, disarrangement of collagen fibers (decreased type I collagen and altered type I collagen/type III collagen ratio) and neoangiogenesis (23)

Corticosteroid injections are widely used in clinical practice. Several studies showed that corticosteroid injections are worse than most of the conservative interventions in the long-term ${ }^{(24)}$.

It is shown in several studies that peritendinous application of HA is an effective therapeutic option for the treatment of chronic tendinopathy ${ }^{(25)}$. HA is one of the main components of synovial fluid, which is produced in the normal tendon sheath and it is a main component of tendon extracellular matrix ${ }^{(26)}$.

We aimed to evaluate the efficacy of HA peritendinous injections versus steroid injections on pain reduction at rest and on movement in patients with painful tendinopathies.

In our study, the mean age of the study groups was around 46 years, about two thirds of the study groups were females, and the three groups were age and sex-matched with no significant difference. The mean disease duration of our study groups was about 1 year. Most of cases had shoulder area tendinopathies, with only about one quarter of the cases had trigger fingers and around $10 \%$ had plantar fasciitis.

In our study, we found that the lowest VAS was recorded in the group of combined HA and steroid injection (group 3) followed by steroid group (group 2) and lastly the group of HA alone (group 1). Group 3 showed early and sustained significant differences compared to group 1 , only late significant difference compared to group 2. On the other hand, there were no significant differences between groups 1 and 2 all over the study duration. This is in agreement with Bernetti et al. ${ }^{(27)}$ who compared the long-term effectiveness of the infiltration of local corticosteroids versus a protocol of one infiltration of local corticosteroid followed by three infiltrations of low molecular weight HA in eleven patients practicing tennis as a hobby, who were diagnosed a humeral epicondylitis. They found that the better way of treatment was the combination of methylprednisolone acetate $40 \mathrm{mg} / \mathrm{ml}$ with $0.8 \mathrm{ml}$ lidocaine plus injection of $1 \mathrm{ml}$ of low HA 10 days later and once a week for two more times. Also, Orlandi $\boldsymbol{e t}$ al. ${ }^{(28)}$, in their study planned to compare the six-month outcome of three different ultrasound-guided treatments for 75 patients with De Quervain's disease (DQD). VAS scale, reduced disability score (quick-DASH), and retinaculum thickness were evaluated at baseline and after one (excluding retinaculum thickness), three, and six months. Patients were randomized into three groups of 25 patients each treated under ultrasound guidance: Group A with $1 \mathrm{ml}$ methylprednisolone acetate, group B with $1 \mathrm{ml}$ methyl-prednisolone acetate +15 day delayed $2 \mathrm{ml}$ saline 0.9 , Group $\mathrm{C}$ with $1 \mathrm{ml}$ methylprednisolone acetate +15 day delayed $2 \mathrm{ml}$ low molecular weight HA. After six months, they concluded that addition of HA to ultrasound guided injections of steroids to treat DQD seems to improve the outcome and to reduce the recurrence rate. 
On the other hand, the study of Liu et al. ${ }^{(29)}$, investigated the effects of HA versus steroid injections for trigger fingers in adults using ultrasound-guided injection. They treated 36 subjects with the diagnosis of trigger finger, randomized into HA and steroid injection groups; both study medications were injected separately via ultrasound guidance with one injection. The classification of trigger grading, pain, functional disability, and patient satisfaction were evaluated before the injection and 3 weeks and 3 months after the injection using VAS scale, Quinnell scale and Michigan Hand Outcome Questionnaire. At the end of the study, ultrasound-guided injection of HA demonstrated promising results for the treatment of trigger fingers.

\section{CONCLUSIONS}

Local injection for tendinopathies by combined HA and steroid gives significantly better and more longstanding effect compared to either HA or steroid alone. On the other hand, monotherapy showed nonsignificant difference between steroid and HA in the management of painful tendinopathy.

\section{Financial support and sponsorship: Nil. Conflict of interest: Nil.}

\section{REFERENCES}

1. Wilson J, Best $\mathbf{T}$ (2005): Common overuse tendon problems: A review and recommendations for treatment. Americal Family Physician, 72 (5): 811-8.

2. Nirschl R, Ashman E (2004): Tennis elbow tendinosis (epicondylitis). Instrumental Course Lectures, 53: 58798.

3. Wober W, Rahlfs V, Buchl $\mathrm{N}$ et al. (1998): Comparative efficacy and safety of the non-steroidal anti-inflammatory drugs nimesulide and diclofenac in patients with acute subdeltoid bursitis and bicipital tendinitis. International Journal of Clinical Practice, 52 (3): 169-75.

4. Petri M, Hufman S, Waser G et al. (2004): Celecoxib effectively treats patients with acute shoulder tendinitis/bursitis. Journal of Rheumatology, 31 (8): 1614-20.

5. Silbernagel K, Thomee R, Thomee $P$ et al. (2001): Eccentric overload training for patients with chronic Achilles tendon pain--a randomised controlled study with reliability testing of the evaluation methods. Scandnacian Journal of Medical Sciences: Sports, 11 (4): 197-206.

6. Ohtori S, Inoue G, Mannoji C et al. (2001): Shock wave application to rat skin induces degeneration and reinnervation of sensory nerve fibres. Neuroscience Letters, 315 (1-2): 57-60.

7. Hay E, Paterson S, Lewis M et al. (1999): Pragmatic randomised controlled trial of local corticosteroid injection and naproxen for treatment of lateral epicondylitis of elbow in primary care. British Medical Journal, 319 (7215): 964-8.

8. Smidt N, van der Windt D, Assendelft W et al. (2002): Corticosteroid injections, physiotherapy, or a wait-andsee policy for lateral epicondylitis: a randomised controlled trial. Lancet, 359 (9307): 657-62.
9. Sanchez M, Anitua E, Orive G et al. (2009): Plateletrich therapies in the treatment of orthopaedic sport injuries. Sports Medicine, 39 (5): 345-54.

10. Paoloni M, Bernetti A, Belelli A et al. (2015): Appropriateness of clinical and organizational criteria for intra-articular injection therapies in osteoarthritis. A Delphi method consensus initiative among experts in Italy. Annals Ist Super Sanita, 51 (2): 131-8.

11. Bhattacharya $\mathrm{D}$, Svechkarev $\mathrm{D}$, Souchek $\mathrm{J}$ et al. (2017): Impact of structurally modifying hyaluronic acid on CD44 interaction. Journal of Mater Chemical Biology, 5 (41): 8183-92.

12. Wu Y, Tang J (2013): Tendon healing, edema, and resistance to flexor tendon gliding: clinical implications. Hand Clinical, 29 (2): 167-78.

13. Petrella R, Cogliano A, Decaria J et al. (2010): Management of Tennis Elbow with sodium hyaluronate periarticular injections. Sports Medicine Arthroscopic Rehabilitation Therapeutic Technology, 2: 4-8.

14. Muneta T, Koga H, Ju Y et al. (2012): Hyaluronan injection therapy for athletic patients with patellar tendinopathy. Journal of Orthopaedic Science, 17 (4): 425-31.

15. Kumai T, Muneta T, Tsuchiya A et al. (2014): The short-term effect after a single injection of highmolecular-weight hyaluronic acid in patients with enthesopathies (lateral epicondylitis, patellar tendinopathy, insertional Achilles tendinopathy, and plantar fasciitis): a preliminary study. Journal of Orthopaedic Science, 19 (4): 603-611.

16. Petrella M, Cogliano A, Petrella R (2009): Original research: long-term efficacy and safety of periarticular hyaluronic acid in acute ankle sprain. Physical and Sports Medicine, 37 (1): 64-70.

17. Merolla G, Bianchi P, Porcellini G (2013): Ultrasoundguided subacromial injections of sodium hyaluronate for the management of rotator cuff tendinopathy: a prospective comparative study with rehabilitation therapy. Musculoskeletal Surgery, 97(1): 49-56.

18. Meloni F, Milia F, Cavazzuti M et al. (2008): Clinical evaluation of sodium hyaluronate in the treatment of patients with sopraspinatus tendinosis under echographic guide: experimental study of periarticular injections. European Journal of Radiology, 68 (1): 170-3.

19. Flores C, Balius R, Alvarez G et al. (2017): Efficacy and Tolerability of Peritendinous Hyaluronic Acid in Patients with Supraspinatus Tendinopathy: a Multicenter, Randomized, Controlled Trial. Sports Medicine Open, 3 (1): 22-26.

20. Maffulli N, Longo U, Loppini M et al. (2010): Current treatment options for tendinopathy. Expert Opinion on Pharmacotherapy, 11 (13): 2177-86.

21. Cook J, Purdam C (2009): Is tendon pathology a continuum? A pathology model to explain the clinical presentation of load-induced tendinopathy. British Journal of Sports Medicine, 43 (6): 409-16.

22. Frizziero A, Vittadini F, Gasparre G et al. (2014): Impact of oestrogen deficiency and aging on tendon: concise review Muscles. Ligaments and Tendons Journal, 4 (3): 324-27.

23. Del Buono A, Battery L, Denaro V et al. (2011): Tendinopathy and inflammation: some truths. International Journal of Immunopathology and Pharmacology, 24 (1): 45-50.

24. Coombes B, Bisset L, Vicenzino B (2010): Efficacy and safety of corticosteroid injections and other injections for 
management of tendinopathy: a systematic review of randomised controlled trials. The Lancet, 376 (9754): 1751-67.

25. Meloni F, Milia F, Cavazzuti M et al. (2008): Clinical evaluation of sodium hyaluronate in the treatment of patients with sopraspinatus tendinosis under echographic guide: experimental study of periarticular injections. European Journal of Radiology, 68 (1): 170-3.

26. Abate M, Schiavone C, Salini V (2014): The use of hyaluronic acid after tendon surgery and in tendinopathies. Bio Med Research International, 14: 1-7.

27. Bernetti A, Mangone M, Paoloni M et al. (2014): Corticosteroid and hyaluronic acid injection therapy in tennis elbow (lateral epicondylalgia). Medicina Dello Sport, 67 (2): 289-95.

28. Orlandi D, Corazza A, Fabbro E et al. (2015): Ultrasound-guided percutaneous injection to treat de Quervain's disease using three different techniques: a randomized controlled trial. European Radiology, 25 (5): 1512-9.

29. Liu D, Tsai M, Lin S et al. (2015): Ultrasound-guided hyaluronic acid injections for trigger finger: A doubleblinded, randomized controlled trial. Archives of Physical Medicine and Rehabilitation, 96 (12): 2120-7. 